\title{
The Plurilingual and Multimodal Management of Participation and Subject Complexity in University CLIL Teamwork
}

\author{
Eulàlia Borràs $^{1} \&$ Emilee Moore ${ }^{2}$ \\ ${ }^{1}$ Polytechnic School, Universitat de Lleida, Igualada, Spain \\ ${ }^{2}$ Faculty of Education, Universitat Autònoma de Barcelona, Bellaterra, Spain \\ Correspondence: Eulàlia Borràs, Polytechnic School, Universitat de Lleida, Campus Igualada, Pla de la Massa 8, \\ 08700 Igualada, Spain.
}

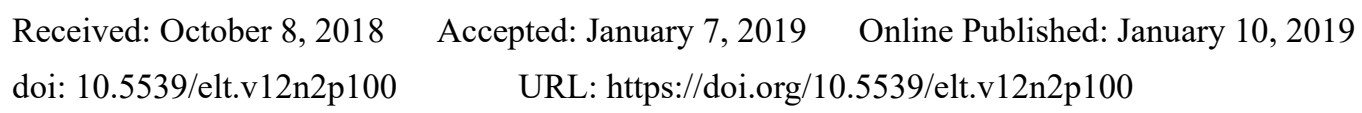

\begin{abstract}
This paper explores the interactions of a groupwork team composed of both local and exchange students, with heterogeneous competence in English, in an English-medium CLIL context at a technical university in Catalonia. Plurilingual and multimodal conversation analysis is used to trace how the students jointly complete an academic task. The research conducted specifically analyses how students categorise themselves and each other in terms of their expertise, and the procedures and resources the students deploy to accomplish the task. The data show that participants' heterogeneous linguistic repertoires are not an obstacle for successfully completing the task, for constructing subject knowledge, or for establishing a climate of mutual understanding and cooperation. The analysis refers to the tension emerging in the data between the interactional principles of progressivity -actions oriented towards task completion- and intersubjectivity -actions oriented towards resolving communicative difficulties. It also focuses on how co-participants mobilise diverse resources from their communicative repertoires, including plurilingual resources, gesture and material artefacts, in managing the task. The main argument put forward is that in instructional environments in which students are expected to build subject matter knowledge using languages that they are simultaneously learning (e.g. CLIL), considering their whole communicative repertoires as valuable resources for their learning is a promising approach.
\end{abstract}

Keywords: progressivity, intersubjectivity, repair, teamwork tasks, international higher education, English as a lingua franca, plurilingualism, multimodality, CLIL

\section{Introduction}

In the current context of internationalisation of higher education, classrooms are spaces in which international students and local students meet and engage academically. This article studies how three students -one local student and two Erasmus exchange students- with heterogeneous linguistic competences in English as a medium of instruction work together in a Content and Language Integrated Learning (CLIL) classroom at a technical university in Catalonia. The students have been assigned an academic task that they must complete with little or no supervision from their instructor. English is used by the teacher in interaction with the students inside and outside of the classroom, the materials provided for the task are in English, and English would commonsensically be the default lingua franca for the student group, two being native Turkish speakers and one a bilingual Catalan-Spanish speaker. Against this backdrop, this article considers general questions such as: How does the participation format and the use of English affect the process and outcome of the task? How do students negotiate the parameters of the work at hand, including the language to be used and their different expertise? What communicative resources besides English do students mobilise to successfully work together in this academic context? More specifically, we are interested in: 1) examining the tension between what we will refer to, drawing on Heritage (2007) and Schegloff (2007), as progressivity and intersubjectivity in the small teamwork interactions studied in this internationalised (Moore, Nussbaum, \& Borràs, 2013) classroom context; and 2) exploring how the focal participants solve the task assigned to them, using English as a lingua franca (ELF), as well as by incorporating other multimodal and plurilingual communicative/cognitive resources in their exchanges.

In the following section of the article, we present our theoretical and methodological orientation, before introducing our empirical procedures, the data analysis, and the results. The article concludes by considering the 
implications of our study for research and practice in internationalised classrooms such as the one studied.

\section{Theoretical and Methodological Framework}

\subsection{Conversation Analysis Theory and Method}

In this article, we draw on conversation analysis (CA), the micro-sociological discipline initiated by Sacks, Schegloff and Jefferson (Sacks, 1972, 1992; Sacks, Schegloff, \& Jefferson, 1974; Schegloff et al., 1977), as both a theoretical approach to social order and a methodological procedure for the study of interaction. The analysis of interactional mechanics and their consequences for speakers and listeners, as well as for our understanding of the context of interactions or of learning processes and outcomes, has been well documented in the literature (e.g. Atkinson \& Heritage, 1984; Markee, 2000; among many others). Conversation analysis studies on interactional practices in higher education are also numerous. The focus of attention of such research has included the analysis of how ELF is used in classrooms (Björkman, 2011; Moore, Borràs, \& Nussbaum, 2013) or how subject and language knowledge is constructed in CLIL classroom contexts in interactional sequences between teacher and student (Berthoud, Gradoux, \& Steffen 2011; Borràs, Moore, Nussbaum \& Patiño, 2012; Moore, Nussbaum \& Borràs, 2013; Veronesi, 2007) or student teamwork (Moore \& Dooly, 2010; Moore, 2014; Deal, 2016).

While CA is in principle agnostic towards external theories, including theories of learning, since its beginnings the field has explored the procedures through which knowledge is displayed, acquired, confirmed and modified by participants in everyday social interaction. According to Kasper (2008), CA contributes two insights for understanding the relationship between social interaction and cognition "by emphasising that the knowledge that people draw on in the concerted management of their situated activities is always embedded in and arises from practical exigencies" (p. 61). The first redefines objects that have traditionally been treated as individual mechanisms in the psychological program -such as memory, perception and learning- as activities that are intrinsically social and situated. The second "treats all cognitive properties of persons as embedded within, and thereby available from, their situated communicative and other forms of activities" (Coulter, 1991, p. 189). Indeed, the complementarity of the CA approach to cognition and Vygostky's socio-cultural learning theory, which emphasises the interpersonal nature of knowledge construction, has been discussed at length in the literature (Mondada \& Pekarek Doehler, 2004; Pekarek Doehler, 2009).

Among other aspects, in this article we explore the relationship between linguistic expertise and content matter expertise, and examine how the mobilisation of plurilingual and multimodal resources configures the organisation of the students' interaction, the distribution of expertise amongst participants, and task completion. In doing so, we draw on the CA notion of membership categorisation (Sacks, 1972, 1992; Antaki \& Widdicombe, 1998), in order to trace how participants themselves assign different roles and attributes to themselves and others in the unfolding interaction. The largest body of work on membership categorisation has been concerned with identities. From the perspective of what Cameron (1990) refers to as 'mythologised sociolinguistics', identity is understood as pre-existing characteristics of people that might determine their behaviour. From a radically different stance, CA's membership categorisation analysis allows identity, including identities related to expertise, to be conceptualised as a situated, interactional accomplishment.

We also draw on interactional approaches to plurilingualism, following the work of authors such as Py, Lüdi, Auer, Mondada, Nussbaum and colleagues (for example Alber \& Py, 1985, 1986; Auer 1984, 1999; Lüdi \& Py, 2003, 2009; Mondada, 2007; Nussbaum \& Unamuno, 2000). Adopting the terminology used by these authors, the corpus that we examine in this study is of an exolingual-plurilingual nature, meaning that the participants orient to assymetries in their plurilingual competences (Coste, Moore, \& Zarate, 1997) and mobilise a series of resources from different named languages (Catalan, Spanish, English, Turkish) in completing the task at hand. Different studies of plurilingual interaction in learning environments have demonstrated how the mobilisation of students' whole plurilingual repertoires contributes positively to knowledge construction (e.g. Gajo, 2007; Masats, Nussbaum, \& Unamuno, 2007; Moore, 2014; Nussbaum \& Unamuno, 2000).

Similarly, we are guided by interactional approaches to English as a lingua franca (ELF) -one medium of plurilingual-exolingual talk. ELF has been defined as "a 'contact language' between persons who share neither a common native tongue nor a common (national) culture, and for whom English is the chosen foreign language of communication" (Firth, 1996, p. 240). ELF is thus considered an emergent, ad hoc variety with no native speakers, lacking many of the features of standard English that are not crucial for international intelligibility (House, 2003; Seidlhofer, 2005). From a CA perspective, lingua franca has been conceptualised as not only raw material for talk in international settings, but also as a local, interactional accomplishment - or a resource whose use and features are a product of the here and now of talk (Firth, 1996; Mondada, 2004; Moore, Nussbaum, \& Borràs, 2013). 
Finally, our research builds on studies of multimodality within conversation analysis (e.g. Goodwin, 2000, 2007; Mondada, 2016). In describing the activities of the students as they work together, we emphasise not only their embodied participation -their gesture, body position, gaze, etc. We also pay attention to how the students orient visually and cognitively to various material artefacts, including a blank sheet of paper for writing answers, a handbag they examine when exploring the physical properties of leather, or a handout with a grid that must be filled in collaboratively. Our analysis suggests, in line with previous CA research, that when participants orient to certain material artefacts, an interactional reorganisation takes place involving their speech, their bodies, other artefacts and the space that surrounds them. By considering both human and non-human actors in interaction, our approach aligns with the new-materialism/post-humanism turn in applied linguistics (e.g. Budach, Kell, \& Patricks, 2015).

\subsection{Progressivity and Intersubjectivity}

The relationship between the principles of progressivity (Schegloff, 2006) and intersubjectivity (Heritage, 2007) is a main focus of our analysis. These principles help understand the intrinsic connection between two characteristics of plurilingual-exolingual talk, including talk in English as a lingua franca, which might seem $a$ priori contradictory. According to Smit (2010), interlocutors struggle to find the midpoint between two opposing poles: a) the need to achieve a communicative goal, and $b$ ) the need to achieve it under the conditions available to them. When communicative resources are limited, more work is needed to achieve understanding; however, this stands in conflict with time and energy constraints (Poulisse, 1997). In this article, we use the term progressivity, on the one hand, as a way of talking about participant's actions oriented to completing the task at hand. On the other hand, intersubjectivity refers broadly to the construction and maintenance of a common worldview. Here, we use the term more specifically to refer to participants' actions oriented towards solving misunderstandings or other communicative difficulties emerging in their interaction.

The principle of progressivity is intimately related to the interactional procedures that Firth (1996) describes as 'let it pass' and 'make it normal'. These procedures refer to how interactional participants treat potentially abnormal features (e.g. "grammatical infelicities" or "unidiomatic clause constructions", Firth, 1996, p. 242) of the unfolding talk as ordinary, either by ignoring them or letting them pass, or incorporating them into their speech, thus making them normal. Moving from one interactional turn to the next without interruption is a measure of progressivity (Schegloff, 2007, pp 14-15).

The principle of intersubjectivity is linked to what Smit (2010), following Poulisse (1997) describes as 'joint forces', or the disposition to work collaboratively. The principle 'joint forces' implies that the participants contribute everything they can to the communicative exchange that is interactionally necessary (Smit, 2010, p. 398). One way that participants join forces for collaborative action is by engaging in repair sequences. Repair is an interactional phenomenon in which the trajectory of talk is altered in order to attend to some aspect of the interaction that puts the maintenance of mutual understanding at risk. While Schegloff et al. (1977) explain that nothing is a priori excluded from the category 'repairable', in this article we focus on repairs that are linguistically focused.

\section{Method}

The data analysed are transcribed extracts from a video recording of a student teamwork session. The recordings were made with a single camera focused on the student group, having obtained informed consent from participants. Conventions proposed by the Research Centre for Plurilingual Interaction and Teaching (GREIP) are used for transcribing talk and multimodal action. These have been developed over the years based on those proposed by Gail Jefferson for CA (Jefferson, 2004). For reasons of clarity, multimodal features are only incorporated into the transcripts when they are relevant for the analysis. Also for clarity, when including sections of the transcript in the narrative, we use standard punctuation representing an approximate interpretation of the interactional data. We do not translate features from languages besides English in the transcripts themselves, but do so in the accompanying analysis. We also do not transcribe non-standard English use phonemically unless it is relevant for the analysis.

The group focused on is made up of a local student, Laia (LAI) and two Erasmus students from Turkey, Ahmet (AHM) and Fatma (FAT), all of whom are studying at a technical university in Catalonia. It should be mentioned that Ahmet is substituted in the middle of the recorded session by Cem (CEM), who is included in one of the extracts. The subject the students are taking is called Resources for Leather Technology, taught by Caterina (CAT). The students had never worked together before and the local student did not know the exchange students.

The recorded class session lasts about 50 minutes and the structure is as follows. First, the teacher proposes student group configurations and assigns them the tasks described on a worksheet that she hands out. Students 
then organise themselves and carry out the task autonomously, while the teacher moves around the class monitoring the groups and offering advice. The task itself consists of filling out a grid with information about the methods of leather tanning (vegetable, chromium, synthetic, gluteraldehyde, etc.) and various parameters for each one (time, percentage of product added, $\mathrm{pH}$, colour, etc.). Throughout the task the participants engage in an ongoing discussion about the main parameters involved in technical chemistry. At the end of the task, the students need to present their conclusions to the whole class group.

\section{Analysis}

The analysis is structured as follows. First, we examine the students' point of departure -that is, how they negotiate the lingua franca they will use for working together as a group, and how they categorise themselves and each other in terms of their linguistic and content matter expertise related to the task at hand. Next, we take a closer look at the mechanisms the students deploy to accomplish the interactional work necessary for successful task completion, taking into account the subject knowledge and English language expertise amongst them, and how they operate within the principles of progressivity and intersubjectivity in doing so. In terms of progressivity, we account for the procedures used by students to move the task forward, despite potential linguistic problems, or what Firth (1996) refers to as 'let it pass' and 'make it normal'. In terms of intersubjectivity, we examine the repair work engaged in by the students, and the cooperative work carried out around a lexical problem. We also examine how plurilingualism and multimodality emerge as both problem solving and interaction structuring resources. In closing the analysis, we show how the distribution of expertise established initially in the students' interaction is re-organised through joint knowledge construction.

\subsection{Orientation to the Task: Categorisations of Expertise in Academic Content and English}

At the beginning of the task, students' interaction is organised around the negotiation of how to go about the work at hand and how to manage it linguistically in a context in which students have heterogeneous plurilingual repertoires. In this section we analyse: (a) how the local student is categorised as lacking competence in English; (b) how the Turkish Erasmus students are categorised as more expert participants; (c) the procedures engaged in to cope with these asymmetries in order to jointly carry out the task.

In Fragment 1, the teacher, Caterina (CAT), presents the task-as-workplan (Breen, 1989) announcing that students should fill in the gaps on their handout with the different tanning methods.

Fragment 1

1. CAT: you need to/ hm::: (.) fill in the bla:nks/ (.) in the table/ (0.5)

2. that I'm going to give youl

3. (1.9)

4. CAT: Laia (.) a: is also (.) ah: studying leather technology so it's going to be

5. AHM: yes

6. FAT: yes

7. (0.9)

8. CAT: helpful $\backslash$ okay

9. (.)

10. LAI: but: I don't understand English $\backslash[($ laughter $))]$

11. FAT: $\quad$ [((laughter))]

12. AHM: [((laughter))]

13. FAT: I'll help you understand

14. CAT: this hopefuly is going to be a collaborative project

14. FAT: yeah $\backslash$

16. (.)

17. AHM: yes $\backslash$

18. CAT: okay/

19. (1.4)

20. LAI: vale〉 
21. (.)

22. FAT: let's fill in the blanks first $\backslash$

In Fragment 1, from lines 1 to 8, the teacher addresses the students, explaining the task and presenting the local student, Laia, as being a student of leather technology, a fact that the two Erasmus students, who come from similar studies, acknowledge in lines 5 and 6. This learning makes Laia a "helpful" (line 8) group member, according to the teacher. The teacher's comment would seem to have the function of presenting Laia as a co-expert, possibly pre-empting the categorisation work to come. In line 10, Laia presents herself as a non-expert knower of English, constructing this category by referring to a lack of linguistic competence: "but I do not understand English". At that moment, the three students laugh in unison, which mitigates Laia's claim to incompetence and shows the positive affiliation of the other students towards the local student. This empathetic stance is further demonstrated with Fatma's offer of assistance in line 13. After the teacher comments that the task should be completed collaboratively (line 14), also in response to Laia's negative self-categorisation, all the participants tacitly agree to continue in English as they collectively focus on the handout in front of them. Laia verbalises this agreement, however, not by using English, but with a Catalan/Spanish "vale" (meaning "ok", line 20). Such plurilingual insertions are a feature of her lingua franca English, as the remainder of the analysis will show.

\subsection{Balancing Progressivity and Intersubjectivity}

The interactional principles of progressivity and intersubjectivity, as we have discussed previously, allow us to conceptualise the competing demands and foci of attention of the student group as they concentrate on the task set for them. The data suggest an extremely collaborative and cohesive working group, which solves communicative obstacles by mobilising resources of diverse nature, including other languages, 'bricolaged' (Alber \& Py, 1986) ELF features (e.g. words coined from other languages), and multimodality. Students' orientation to progressivity is displayed in the range of interactional actions that they take to drive the task towards its resolution, and includes indicators such as efficiency, immediacy and simplicity. Orientation to intersubjectivity, on the other hand, is observed in their actions attending to the needs of other participants, including indicators such as equity (vs. efficiency), collaboration (vs. immediacy), and complexity (vs. simplicity). In this paper we intend to show how participants mobilise all their available resources to maintain the balance between the duality of orienting themselves towards the task or orienting themselves towards cooperation between heterogeneous participants.

In this section of the analysis, we study some of the precise procedures through which the students' orientation to these two principles is displayed. We focus first on the principle of progressivity.

\subsubsection{Progressivity: Participant Alignment}

The first feature that draws attention when examining the data is the frequency with which the participants agree, either through negotiation, as in some of the fragments presented below, or by means of the explicitation of consensus without negotiation, as in Fragment 2.

In this fragment, Ahmet is describing one of the tanning processes, and introduces the idea that it requires chrome III and not chrome VI.

Fragment 2

1. AHM: for example we use a: e:::chrome threel

2. LAI: sí

3. AHM: no chrome six $\$

4. (.)

5. FAT: yes $\backslash$

6. (.)

7. FAT: because it's cancerigen

8. AHM: yes\

Ahmet's turns are met with the other participants' immediate alignment (Laia's "sí" meaning "yes" in line 2, Fatma's "yes" in line 5). Fatma also helps extend the information put forward by Ahmet, indicating that chrome VI is not used because is cancerigenous (line 7), which Ahmet immediately agrees with (line 8).

4.2.2. Progressivity: 'Let it Pass' and 'Make it Normal' 
Making a non-issue of bricolaged language uses is the norm in the corpus of data that we have studied -it is unusual for any linguistic 'errors' to be explicitly highlighted by the participants. When errors are signaled out, it is to ensure that communication can progress beyond a 'fatal error'. In fact, the normalisation of linguistic bricolage predominates so strongly in the data examined that bricolaged features (mainly lexicon) that emerge in the interaction are normalised as part of the participants' ELF.

Fragment 3 is an extract from the final discussion in which the students present their conclusions to the whole class, and includes turns from Laia, Ahmet and Cem, who we have introduced already, as well as from another classmate (SEL).

Fragment 3

1. CEM: can we use em (.) chrome tanning instead of-

2. AHM: but (.) I prefer (.) I prefer vegetablel

3. (0.5)

4. CEM: ((to AHM) you prefer vegetable/)

5. (1.3)

6. LAI: why/

7. (.)

8. AHM: I repeat

9. (1.7)

10. LAI: ((to AHM) you prefer $\left[+\mathrm{v}^{6}\right.$ edzetal + o no/)

11. (1.3)

12. AHM: I- (.) I prefer veget- (.) [+v'edzetal+]

13. LAI: $\left[\mathrm{si}^{\prime} /\right]()+.\mathrm{v}^{`}$ edzetal $+/().(($ to SEL) and you/)

14. (0.7)

15. SEL: chromium।

16. (1.2)

17. AHM: a- (.) chrome best but- (.) I $n-($.$) I prefer +v^{`}$ edzetal +1

In the second line, Ahmet announces that he prefers vegetable tanning using the standard English word "vegetable". In line 4, Cem questions this affirmation, also using the standard "vegetable". In line 6, Laia takes the floor to ask Ahmet "why", which seems to be understood by Ahmet as a request for repetition (line 8). In line 10, Laia rephrases, asking Ahmet to clarify if he prefers vegetable tanning or not. In doing so, Laia does not use the word her peers have been using, but instead coins the lexical item " $/ \mathrm{v}^{6}$ edzetal $/$ ", presumably a creative adaptation from the Catalan word for vegetable -vegetal, pronounced approximately as /bedze 'tal/. In line 12, Ahmet reiterates his preference for vegetable tanning. In this line, he doubts over which form of the word to use -the standard "vegetable" which he starts to voice before self-interrupting, or the non-standard "/v"edzetal/" introduced by Laia, which he opts for at the end of the turn. In the following line, Laia agrees with Ahmet ("sí", meaning "yes"), before repeating the non-standard word. In line 17, Ahmet again ratifies and normalises the use of the bricolaged alternative " $/ \mathrm{v}$ "edzetal/". The fragment thus shows how the participants not only tolerate linguistic bricolage, but incorporate it as a resource at their disposal for completing the task.

\subsubsection{Intersubjectivity: Joint Forces in Doing Repair}

The participants in the data studied display great interest in collaborating, by repairing, clarifying, or specifying their emerging turns at talk. In the following two sections, we focus on how the students manage the problem of achieving and maintaining mutual understanding, focusing on repair. CA literature (e.g. Schegloff et al., 1977) identifies different types of repair, depending on who initiates it (self or other) and who completes it (self or other), and shows how self-initiated self-repair is least threatening to one's face, while other-initiated other-repair is the most threatening repair type. In this section we focus on an instance of other-initiated other-repair, which has clear implications for the emerging categorisations of participants as experts and non-experts. In the corpus studied, as well as in the fragment analysed, the international students tend to be the participants who produce other-repairs.

As we have mentioned previously, form-focused repair is not common in the data -like in Fragment 3, 
participants tend to incorporate non-standard uses of English as a normal part of their shared ELF variety. When repair of linguistic form does emerge, it tends to focus on subject specific terminology only, whose misuse is considered a 'fatal error'.

Repair of content errors is more common in the corpus, although using mitigating interactional strategies when carried out by others rather than by self. In the following fragment, the students are discussing the outcomes of different tanning processes (final products obtained, their characteristics etc.).

\section{Fragment 4}

1. FAT: all process is finished (.) and leather is coming (.) how can use this $\backslash$ (.) e:h 2 . how can see that

3. (0.4)

4. FAT: it's stro:ng (.) normal leather

5. LAI: ja: jal

6. FAT: for [example jacket]

7. LAI: [during during] the:

8. (0.4)

9. LAI: during

10. (.)

11. FAT: not during $\backslash$

12. (0.5)

13. FAT: hm:: i:f (.) for example your jacket (.) leather [jacket]]

14. AHM: [yes \] it's leather

15. (.)

16. FAT: aha (.) eh:

17. (.)

18. FAT: which differences between the textile and the leather (.) I think (.) they

19. mean $\backslash$ (.) it means that $\backslash$

Fatma argues that it is when the leather manufacturing process is finished that its characteristics, such as strength, can be evaluated (lines 1-4) Laia shows her agreement ("ja ja", meaning "yeah yeah") in line 5, then, in an attempt to reformulate and show that she understands Fatma's reasoning, initiates a statement using word "during" (lines 7 and 9). Fatma takes advantage of a brief silence to repair Laia's contribution, "not during" (line 11). Fatma marks her disagreement unambiguously because the word "during" introduces an idea that is in total disagreement with the one that she had expressed at the beginning of the fragment. That is, it is when the leather tanning process "is finished" (and not "during" the processing of the leather) when the characteristics of the product may be assessed. From line 13, Fatma reformulates and exemplifies the question about the characteristics that the students are working on, ending with a mitigating "I think they mean it means that", with the "I think" introducing uncertainty in her interpretation and helping to position her on more equal standing to Laia.

\subsubsection{Intersubjectivity: Plurilingualism and Multimodality as Resources}

In this section, we explore the diversity of resources mobilised by participants in working on the task together despite linguistic asymmetries. In previous sections, we have already described how participants incorporate non-standard English forms and words from other languages in their shared ELF repertoire. This is especially the case in Laia's turns at interaction in the data examined in this article, however the corpus also includes instances when her foreign peers employ similar resources. Here, we focus more closely on how gesture and non-human actors also take part in the students' interaction. To do so, we analyse an instance of how the students deal with what they orient to as a potential non-understanding (Moore, 2016) of a particular word in a participant's turn.

In the following fragment, the students have been listing different products made from chromium-tanned leather. The fragment begins with Fatma voicing the word "gloves".

Fragment 4

1. FAT: gloves $\backslash$ 
2. AHM: gloves

3. LAI: glo- síl

4. FAT: gloves $\backslash$

5. (1.1)

6. LAI: gloves/

7. AHM: [((pretending to put on gloves) gloves $)]$

8. FAT: [((pretending to put on gloves) gloves $)$ ]

9. LAI: [((looks at the hands of other participants))

10. LAI: hm::/ (.) gloves

11. AHM: for (.) hand

12. FAT: for hand $\backslash$

13. (0.5)

14. LAI: AH VAle $\backslash$ (.) guants $\backslash$ (.) okay $\backslash$ (.) hm:

15. LAI: ((takes gloves from handbag))

16. LAI: ((showing her gloves) these $\backslash)=$

17. FAT: $=$ yes $\backslash$

18. AHM: yes\gloves $\backslash$ yeah $\backslash$

19. LAI: valel

20. (3.3) ((all look at the worksheet))

21. LAI: vale $\backslash$ (.) other $\backslash$ (.) other question $\backslash$

The fragment begins with Fatma, then Ahmet, naming "gloves" as one answer to the question being worked on. In line 3, Laia seems to agree with the suggestion ("sí", meaning "yes") and tries to repeat the word, but cuts it off. This leads to repetition of the word "gloves" by Fatma in line 5. In line 6, Laia seeks clarification of either the pronunciation or the meaning of the word, displayed through her rising intonation. Her peers interpret that the problem is non-understanding, and use gesture to symbolise the action of putting gloves on their hands, while Laia watches. In line 10, Laia shows that the pronunciation of the word is not a problem for her, although her rising intonation on "hm" suggests she is still uncertain about the word's meaning. Her peers clarify that gloves are used "for hand [sic]". Their assistance is effective, as Laia's "ah vale", meaning "ah ok", in line 14 shows a cognitive change of state from non-understanding to understanding. She further translates the word into Catalan, "guants", before taking some gloves from her bag and showing them to her peers for confirmation. The non-understanding is taken to be resolved with the three students' voicing their readiness to move on in lines 17-19 (Fatma's emphatic “yes", Ahmet's “yes, gloves, yeah", and Laia's "vale", meaning “ok"). Return to the academic task is marked by the students' visual orientation to the handout on the table in front of them. Thus multimodal resources (hand gestures, the gloves) not only help the students to achieve mutual understanding, but are also agentive in structuring the interaction (the handout).

\subsection{Joint Knowledge Construction and Redistribution of Expertise}

In this final section of the analysis we explore the relationship between linguistic expertise and subject matter expertise, and examine how the mobilisation of plurilingual and multimodal resources in this ELF interactional context adjusts the organisation of the action and the distribution of expertise among the participants. As we have already noted, although potential language problems are usually addressed explicitly in the students' interaction, the categorisation work that took place at the beginning of the students' task together contributed to an interactional framework in which Laia, the local student, is positioned as a non-expert knower of English from the outset. In contrast, Fatma emerged as the lead expert. Our data suggests that categorisations of participant's linguistic expertise also influence the perception that co-participants have of their subject matter expertise. Thus, the data shows that Fatma's relative competence in English contributes to her being positioned as expert in the academic content as well. In this section, we focus on how Laia manages to mobilise her own subject matter expertise in a way that allows her to challenge the non-expert identity attributed to her based on her lower proficiency in English.

In the following fragment, the students are discussing the resulting colours of tanned leather, and Laia is 
presenting her point that the colour depends on whether the skins have undergone aldehyde tanning or not.

Fragment 10

1. LAI: what colour is/ (.) vale $\backslash$ (.) colour (.) and this (.) yellow and:

2. (.)

3. FAT: dark [white/]

4. LAI: [but it] depend de (.) aldehid $\backslash$

5. FAT: is depend on a- [aldehyde] but normally white/

6. LAI: [aldehid]

7. (1.7)

8. LAI: for example gluteraldehid is: hm::: ((touches handout and moves her finger on 9. it while looking at Fatma))

10. FAT: whitel

11. (.)

12. LAI: white no/(.) whitel(.) whitel

13. ((Fatma touches handout))

14. FAT: I remember whitel

15. AHM: yes $\backslash$

16. LAI: gluteraldehid is white

17. (1.0)

18. LAI: an[d:]

19. FAT: [for]mal-

20. LAI: for examp- all of- alde:: (.) aldehid is (.) a little yellow

21. (0.6)

22. FAT: okayl(.) so white [and: $x x]$

23. AHM: [a little yellowl]

24. LAI: $\underline{\text { sí: }}$

25. (1.4)

26. LAI: in the middle de yellow and: whitel

The fragment begins with Laia referring to the question at hand, and initially suggesting the colour of the tanned leather to be "yellow and" (line 1). In line 3, Fatma suggests "dark white". Laia responds in line 4 to Fatma arguing that the final colour of the leather depends on the aldehyde, an argument she makes by inserting words in Catalan ("depend de aldehid", meaning "depends on aldehyde"). Fatma accepts Laia's point by repeating it, but nonetheless reaffirms her argument that the colour is "normally white" (line 5). From line 8 to 16, Laia responds to Fatma's suggestion and elaborates on her own argument. She firstly makes the point that leather resulting from gluteraldehyde ("gluteraldehid" in Catalan) tanning is white. In doing so, she makes use of the white handout on the table to engage with Fatma in a collaborative search for the word "white". Her peers agree with her in lines 14 and 15, and Fatma begins to add that leather resulting from formaldehyde tanning is also white in line 19. In overlap with Fatma, from line 18, Laia returns to her own argument that not all leather is white. She again gives the example of leather that has undergone aldehyde ("aldehid" in Catalan) tanning, which she claims is "a little yellow". Fatma and Ahmed accept this point in lines 22 and 23, agreeing on the co-enunciated response "white and a little yellow". The elongation and flat intonation on Laia's "sí" (meaning "yes") in line 24 suggests she is not entirely convinced, and after a pause she suggests instead the response "in the middle de (meaning "of") yellow and white". Thus, despite the difficulty Laia displays in speaking English, her subject matter expertise, together with expert recourse to her multimodal and plurilingual repertoire in getting her argument across, see her legitimised in the group as a fellow expert.

\section{Conclusions}

The analysis presented in this article shows how a student group, made up of a local and two international 
members, manage to achieve their communicative and cognitive goals in an ELF university classroom context in which participants have asymmetrical language skills. The resources displayed by them in managing their interaction and the demands of the task include linguistic bricolage, insertions in other languages, gestures, and various artifacts. The data suggest that it is possible to achieve interactional and cognitive equilibrium in academic situations in which linguistic asymmetries are marked.

The data show how asymmetries in the students' competence in English gave rise to a remarkably cooperative work environment. Participants progressed through the task at hand, using the interactional strategy of letting supposed linguistic 'errors' pass, or making them normal. Such potential errors included word coinages resulting from processes of linguistic bricolage -which, we have seen, even become incorporated into the students' shared ELF variety- or direct insertions or words from other languages. At the same time, the participants oriented to the need to maintain a climate of mutual understanding, by joining their forces to engage in repair work. Repair sequences, nonetheless, tended to focus on 'fatal errors' in the academic content being constructed, rather than on language.

We have also analysed how the participants organise and reorganise the interactional framework, and in doing so construct categorisations of themselves and their peers as experts or otherwise in relation to the task at hand. We focused in particular on how Laia repositions herself, and is repositioned by others, as an expert in the subject matter, despite her difficulties speaking English. The data show how this re-categorisation was possible thanks to Laia being able to mobilise her plurilingual and multimodal repertoire for engaging with her peers on the task.

The main argument, then, is that in instructional environments in which students are expected to build subject matter knowledge using languages that they are simultaneously learning (e.g. CLIL), considering their whole communicative repertoires as valuable resources for their learning seems like a promising approach.

\section{References}

Alber, J.-L., \& Py, B. (1985). Interlangue et conversation exolingue. Cahiers du Departement des Langues et des Sciences du Langage, 1, 30-47

Alber, J.-L., \& Py, B. (1986). Vers un modèle exolingue de la communication interculturelle. Études de Linguistique Apliquée, 61, 78-90.

Antaki, C., \& Widdicombe, S. (Eds.) (1998). Identities in talk. London: Sage Publications.

Atkinson, J. M., \& Heritage, J. (Eds.) (1984). Structure of social action: Studies in conversation analysis. Cambridge: Cambridge University Press.

Auer, P. (1984). Bilingual conversation. Amsterdam: Benjamins. https://doi.org/10.1075/pb.v.8

Auer, P. (1999). From code-switching via language mixing to fused lects: toward a dynamic typology of bilingual speech. International Journal of Bilingualism, 3(4), 309-332. https://doi.org/10.1177/1367006 9990030040101

Budach, G., Kell, C., \& Patricks, D. (Eds.) (2015). Objects and language in trans-contextual communication. Social Semiotics, 25(4), 387-400. https://doi.org/10.1080/10350330.2015.1059579

Berthoud, A. C., Gradoux, X., \& Steffen, G. (Eds.) (2011). Plurilinguisme et construction des savoirs. Cahiers de l'ILSL, 30.

Björkman, B. (2011). Pragmatic strategies in English as an academic lingua franca: Ways of achieving communicative effectiveness? Journal of Pragmatics, 43(4), 950-964. https://doi.org/10.1016/j.pragm a.2010.07.033

Borràs, E., Moore, E., Nussbaum, L., \& Patiño, A. (2012). Emergence de modes plurilingues dans des cours universitaires en L2. In L. Mondada, \& L. Nussbaum (Eds.), Interactions cosmopolites: L'Organisation de la participation plurilingue (pp. 63-98). Editions Lambert Lucas: Limoges.

Breen, M. (1989). The evaluation cycle for language learning. In R. K. Johnson (Ed.), The second language curriculum. Cambridge, UK: Cambridge University Press. https://doi.org/10.1017/CBO9781139524520.014

Cameron, D. (1990). Demythologizing sociolinguistics: Why language does not reflect society. In J. E. Joseph, \& T. J. Taylor (Eds.), Ideologies of language (pp. 79-93). New York: Routledge.

Coste, D., Moore, D., \& Zarate, G. (1997). Competence plurilingue et pluriculturelle. Stroudsbourg: Conseil de l'Europe.

Coulter, J. (1991). Cognition: Cognition in ethnomethodological mode. In C. Button (Ed.), Ethnomethodology 
and the human sciences (pp. 176-196). Cambridge: Cambridge University Press. https://doi.org/10.1017/CB O9780511611827.009

Deal, M. (2016). Student interaction during group work in a multilingual university setting. Suggestions, epistemic orientations and scaffolding behaviors ( $\mathrm{PhD}$ dissertation). Universitat Autònoma de Barcelona. Retrieved from https://www.educacion.gob.es/teseo/imprimirFicheroTesis.do?idFichero=whKyM2FSGo8\% $3 \mathrm{D}$

Firth, A. (1996). The discursive accomplishment of normality: On 'lingua franca' English and conversation analysis. Journal of Pragmatics, 26, 237-259. https://doi.org/10.1016/0378-2166(96)00014-8

Gajo, L. (2007). Linguistic knowledge and subject knowledge: How does bilingualism contribute to subject development? International Journal of Bilingual Education and Bilingualism, 10(5), 563-581. https://doi.org/10.2167/beb460.0

Goodwin, C. (2000). Action and embodiment within situated human interaction. Journal of Pragmatics, 32, 1489-1522. https://doi.org/10.1016/S0378-2166(99)00096-X

Goodwin, C. (2007). Participation, stance and affect in the organization of activities. Discourse \& Society, 18 , 53-73. https://doi.org/10.1177/0957926507069457

Heritage, J. (2007). Intersubjectivity and progressivity in person (and place) reference. In N. J. Enfield, \& S. Levinson (Eds.), Person reference in interaction: Linguistic, cultural, and pocial Perspectives (pp. 255-280). Cambridge: Cambridge University Press.

House, J. (2003). English as a lingua franca: A threat to multilingualism? Journal of Sociolinguistics, 7(4), 556-578. https://doi.org/10.1111/j.1467-9841.2003.00242.x

Jefferson, G. (2004). Glossary of transcript symbols with an introduction. In G. H. Lerner (Ed.), Conversation analysis: Studies from the first generation (pp. 13-23). Philadelphia: John Benjamins. https://doi.org/10.10 75/pbns.125.02jef

Kasper, G. (2008). Discourse and socially shared cognition. In J. Cenoz, \& N. H. Hornberger (Eds.), Encyclopedia of language and education (2nd ed., Vol 6). Knowledge about language (pp. 59-78). New York: Springer. https://doi.org/10.1007/978-0-387-30424-3_139

Lüdi, G., \& Py, B. (2003). Etre bilingue. Bern: Peter Lang. https://doi.org/10.21832/9781853596315-013

Lüdi, G., \& Py, B. (2009). To be or not to be ... a plurilingual speaker. International Journal of Multilingualism, 6(2), 154-167. https://doi.org/10.1080/14790710902846715

Markee, N. (2000). Conversation analysis. New Jersey: Lawrence Erlbaum.

Masats, D., Nussbaum, L., \& Unamuno, V. (2007). When activity shapes the repertoire of second language learners. EUROSLA Yearbook, 7, 121-147. https://doi.org/10.1075/eurosla.7.08mas

Mondada, L. (2004). Ways of 'doing being plurilingual' in international work meetings. In R. Gardner, \& J. Wagner (Eds.), Second language conversations (pp. 18-39). London: Continuum.

Mondada, L. (2007). Bilingualism and the analysis of talk at work: Code-switching as a resource for the organization of action and interaction. In M. Heller (Ed.), Bilingualism: A social approach (pp. 297-318). New York: Palgrave. https://doi.org/10.1057/9780230596047_14

Mondada, L. (2016). Multimodal resources and the organization of social interaction. In A. Rocci, \& L. De Saussure (Eds.), Handbooks of communication science (pp. 329-350). Berlin: De Gruyter. https://doi.org/10.1515/9783110255478-018

Mondada, L., \& Pekarek Doehler, S. (2004). Second language acquisition as situated practice: Task accomplishment in the French second language classroom. Modern Language Journal, 88(4), 501-518. https://doi.org/10.1111/j.0026-7902.2004.t01-15-.x

Moore, E. (2014). Constructing content and language knowledge in plurilingual student teamwork: Situated and longitudinal perspectives. International Journal of Bilingual Education and Bilingualism, 17(5), 586-609. https://doi.org/10.1080/13670050.2013.860947

Moore, E. (2016). Language learning in 'the wild' in transnational encounters. RESLA: Revista Española de Lingüistica Aplicada/Spanish Journal of Applied Linguistics, 28(2), 38-415.

Moore, E., Borràs, E., \& Nussbaum, L. (2013). Plurilingual resources in lingua franca talk: An interactionist perspective. In H. Haberland, D. Lønsmann, \& B. Preisler (Eds.), Language alternation, language choice 
and language encounter in international tertiary education (pp. 53-84). Dordrecht: Springer. https://doi.org/10.1007/978-94-007-6476-7_3

Moore, E., \& Dooly, M. (2010). 'How do the apples reproduce (themselves)?' How teacher trainees negotiate language, content, and membership in a CLIL science education classroom at a multilingual university. Journal of Language, Identity \& Education, 9(1), 58-79. https://doi.org/10.1080/15348450903523591

Moore, E., Nussbaum, L., \& Borràs, E. (2013). Plurilingual teaching and learning practices in 'internationalised' university lectures. International Journal of Bilingual Education and Bilingualism, 16(4), 471-493. https://doi.org/10.1080/13670050.2012.702724

Nussbaum, L., \& Unamuno, V. (2000). Fluidité et complexité dans la construction du discours entre apprenants de langues étrangères, Acquisition et Interaction en Langue Etrangère, 12, 27-49.

Pekarek Doehler, S. (2009). Mediation revisited: The interactive organization of mediation in learning environments. Mind, Culture, and Activity, 9(1), 22-42. https://doi.org/10.1207/S15327884MCA0901_03

Poulisse, N. (1997). Compensatory Strategies and the Principles of Clarity and Economy. In G. Kasper, \& K. Eric (Eds.), Communication strategies: Psycholinguistic and sociolinguistic perspectives. (pp. 49-64). Edinburgh: Longman.

Sacks, H. (1972). An initial investigation of the usability of conversational materials for doing sociology. In D. Sudnow (Ed.), Studies in Social Interaction (pp. 31-74). New York: Free Press.

Sacks, H. (1992). Lectures on conversation. Edited by G. Jefferson. Oxford: Basil Blackwell.

Sacks, H., Schegloff, E. A., \& Jefferson, G. (1974). A simplest systematics for the organization of turn-taking for conversation. Language, 50(4), 696-735. https://doi.org/10.2307/412243

Schegloff, E. A. (2006). Interaction: The infrastructure for social institutions, the natural ecological niche for language and the arena in which culture is enacted. In N. J. Enfield, \& S. C. Levinson (Eds.), The roots of human sociality: Culture, cognition and interaction. New York: Berg.

Schegloff, E. A. (2007). Sequence organization in interaction: A primer in conversation analysis (vol. 1). Cambridge: Cambridge University Press. https://doi.org/10.1017/CBO9780511791208

Schegloff, E. A., Jefferson, G., \& Sacks, H. (1977). The preference for self-correction in the organization of repair in conversation. Language, 53, 361-382. https://doi.org/10.2307/413107

Seidlhofer, B. (2005). English as a lingua franca. ELT Journal, 59(4), 339-341. https://doi.org/10.1093/elt/cci064

Smit, U. (2010). English as a lingua franca in higher education: A longitudinal study of classroom discourse. Berlin: Mouton de Gruyter. https://doi.org/10.1515/9783110215519

Veronesi, D. (2007). Movimento nello spazio, prossemica e risorse interazionali: un'analisi preliminare del rapporto tra modalità in contesti didattici accademici. Bulletin Suisse de Linguistique Appliquée, 85, $107-130$.

\section{Appendix A}

\section{Transcription conventions used in this article}

1. Intonation:

a. Falling: \

b. Rising: /

c. Maintained: no symbol

2. Pauses:

a. Timed ( $\mathrm{n}^{\mathrm{o}}$ seconds, more than $1 / 2$ second): (0.5)

b. Untimed or less than $1 / 2$ second micro: (.)

3. Overlapping: [text]

[overlap]

4. Latching: $=$

5. Interruption: text- 
6. Lengthening of a syllable: te:xt

7. LOUD

8. emphatic

9. Incomprehensible fragment: $\mathrm{xx}$ (depending on length)

10. Approximate phonetic transciption: + te: $x t+$

11. Pseudonom of speaker: STU:

12. Transcriber's comments: ((comment)) or ((comment) affected fragment)

\section{Copyrights}

Copyright for this article is retained by the author(s), with first publication rights granted to the journal.

This is an open-access article distributed under the terms and conditions of the Creative Commons Attribution license (http://creativecommons.org/licenses/by/4.0/). 